\title{
A longitudinal study on the Ghislenghien disaster in Belgium: strengths and weaknesses of the study design and influence on response rate
}

\author{
by \\ Versporten APR ${ }^{1}$, De Soir $E^{2}$, Zech $E^{3}$, Van Oyen $\mathrm{H}^{1}$
}

\begin{abstract}
Background

A longitudinal study was conducted in order to assess the impact of the Ghislenghien disaster (Belgium) on physical, mental and social health, and to evaluate the prevalence of Post-Traumatic Stress Disorder (PTSD) in the affected population.
\end{abstract}

Objectives

To describe the set up of the study, to report on the strengths and weaknesses of the methodology employed and its influence on response rate. To clarify the importance of the study for the management of disasters.

\section{Methods/Design}

The study included adults ( $\geq 15$ years) and children (8-14 years) at risk of developing adverse health effects related to the disaster. Subjects were connected to the disaster through their geographical or professional proximity as well as connections through relatives. Questionnaires were sent by regular mail 5 months and 14 months after the disaster. Pearson Chi square tests were used to investigate whether the response rate at 14 months depended on the exposure classification.

Results

The response rate at household level was respectively $18 \%$ ( $n=607$ families) and 56\% ( $n=338$ families) 5 months and 14 months after the disaster. Response rate at the follow up period did not significantly differ by exposure classification.

\section{Discussion}

This paper discusses the difficulties and challenges encountered during the design of the study. It discusses the determinants of response in relation to disaster related characteristics. It further provides an overview of lessons learnt and the significance of the study for the management of large scale emergencies.

\footnotetext{
1 Scientific Institute of Public Health, Direction Public Health and Surveillance, Brussels, Belgium

2 Royal Military Academy, Department of Behavioral Sciences, The Stress and Trauma Research Center, Brussels, Belgium

3 Université catholique de Louvain, Faculty of Psychology, Louvain-la-Neuve, Belgium

Correspondence: ann.versporten@iph.fgov.be
} 


\section{Keywords}

Technological disaster, exposure classification, gas explosion, longitudinal study, response rate

\section{Background}

On July 30th, 2004, an accidental gas leakage occurred in a natural gas pipe under high pressure (80 bars) which passed under the industrial zone of Ghislenghien in the Walloon region of Belgium. This technological disaster killed 24 people; mainly factory workers, firefighters, and a police officer. About 132 people were wounded, many suffered severe burn injuries. Most of the wounded victims were factory workers, firefighters, police officers, and car drivers passing by at that moment on a highway 500 metres from the epicentre of the gas explosion. There was no evidence of additional chemical, air and water contamination. This disaster disrupted the life of those victims and their families physically, emotionally, and mentally (1). The disaster can be considered to be one of the deadliest collective emergencies in Belgium since the mine disaster of the 'Bois du Cazier' in 1956 and the Innovation fire in Brussels 1967.

\section{Introduction}

Disasters cause physical harm and can result in deaths, injuries, and illnesses. Furthermore they can have profound psychosocial impact. Nowadays, many industrialised countries have developed procedures to evaluate the consequences of disasters on the physical, emotional, and mental health of affected people. The problems experienced by disaster survivors are now interpreted in their medical and psychological context, serving as a basis for systematic and structured action by governments. In Belgium, the disaster of Ghislenghien in part has led to the scientific measurement and description of disaster-related health effects, and the improvement of post-impact health care delivery (2).

According to Noji (1995) (3) disaster epidemiology aims to measure and describe the health effects of disasters and the factors contributing to these effects. Based on this description, this longitudinal study on the disaster of Ghislenghien evaluated the overall impact of the disaster on the general health of the affected population, with a special focus on mental health. It further provided "the Belgian Federal Public Service Health, Food Chain Safety and Environment" with the necessary information to improve and harmonise disaster aid structures in Belgium. The current study was carried out by the Institute of Public Health Unit of Epidemiology in collaboration with the Faculty of Clinical Psychology of the Catholic University of Louvain and the Stress and Trauma Research Centre of the Royal Military Academy.

This paper aims to report on the methodology employed, to describe the composition of the study population, the design of the questionnaires, the classification of the degree of exposure to the disaster and the health endpoints investigated. Results on the response rate 
are reported and compared to similar research. Strengths and weaknesses of the employed methodology are discussed. Finally, the paper provides an overview of some lessons learnt and the significance of the study for the management of large scale emergencies.

\section{Methodology}

Study population

Since victims are difficult to define and the denominator usually is unclear in the direct aftermath of disasters (4), our target group composed of all potential victims of the Ghislenghien gas explosion. They included residents living near the industrial site and employees of companies located on the industrial site, as well as their family members living at the same address, including children from 8 to 14 years old. We also targeted family members of deceased and injured persons. All of them were connected with the disaster through a geographical or professional proximity as well as connections through relatives.

The study population was composed using three types of records. The first were the inhabitants living up to maximum $5 \mathrm{~km}$ away from the explosion epicentre ( $n=6382$ adults and 721 children). The information was made available by the municipalities of the declared disaster area. Residents originated from the municipalities of Ath, Silly and Lessines. Secondly, 11 companies located on the industrial ground of Ghislenghien were contacted. Four companies sent administrative lists. All employees, whether or not present during the explosion, as well as students working temporarily during that period were included in the study population ( $\mathrm{n}=606$ adults and 96 children). Finally, the identification of victims and family members was done using a listing of people who identified themselves to an emergency service or another aid service ( $n=159$ adults and 3 children). Those lists were made available by services concerned under the coordination of the Federal Commission of Psychosocial Help.

Household composition was not known for all families; a standard number of 6 questionnaires were sent to those households ( $n=158$ families). Excluded from the study population were children below the age of 8 years and people who were on the site as either firemen, policemen, or from the medical intervention team. Participation to the study was voluntary. The individuals agreed to participate in the study by sending a consent form to the Institute of Public Health or by simply filling in and sending back the questionnaire.

Longitudinal study design

Auto-questionnaires were sent by regular mail services to 3,448 households in December 2004, 5 months after the disaster, The families comprised of 7,148 persons aged 15 years and older and of 820 children; aged 8 to 14 years (Table 1 ).

A follow-up assessment during September 2005 enabled the evaluation of changes in health impact between the period 5 to 14 months after the disaster. The second questionnaire was sent to all people who returned the first questionnaire as well as all their household members 
(whether or not they had replied to the $1^{\text {st }}$ questionnaire). As such, we enlarged our initial sample of respondents by 238 adults and 12 children who did not respond to the $1^{\text {st }}$ questionnaire. A reminder was sent in January 2006 with the aim of achieving a response rate of more than $50 \%$.

Table 1. Response rate 5 months and 14 months after the disaster

\begin{tabular}{|l|l|l|l|l|}
\hline \multirow{2}{*}{} & \multicolumn{2}{|l|}{ Questionnaires sent } & \multicolumn{2}{l|}{ Response rate } \\
\cline { 2 - 5 } & $\begin{array}{l}5 \text { months after } \\
\text { disaster }\end{array}$ & $\begin{array}{l}14 \text { months after } \\
\text { disaster }\end{array}$ & $\begin{array}{l}5 \text { months after } \\
\text { disaster }\end{array}$ & $\begin{array}{l}14 \text { months after } \\
\text { disaster }\end{array}$ \\
\hline N households & 3448 & 609 & $607(18 \%)$ & $338(56 \%)$ \\
\hline N adults ( $\geq 15$ year) & 7148 & 1265 & $1027(14 \%)$ & $579(46 \%)$ \\
\hline N children (8-14 year) & 820 & 140 & $128(16 \%)$ & $74(53 \%)$ \\
\hline
\end{tabular}

Table 2. Set of questions used during first and second questionnaire

\begin{tabular}{|c|c|c|c|c|}
\hline & \multicolumn{2}{|c|}{ Adults $\geq 15$ years } & \multicolumn{2}{|c|}{ Children $8-14$ years } \\
\hline & $\begin{array}{l}5 \text { months } \\
\text { after } \\
\text { disaster }\end{array}$ & $\begin{array}{l}14 \text { months } \\
\text { after } \\
\text { disaster }\end{array}$ & $\begin{array}{l}5 \text { months } \\
\text { after } \\
\text { disaster }\end{array}$ & $\begin{array}{l}14 \text { months } \\
\text { after } \\
\text { disaster }\end{array}$ \\
\hline Socio-demographic information* & $\mathrm{X}$ & $\mathrm{X}$ & $\mathrm{X}$ & $\mathrm{X}$ \\
\hline Absenteeism at work and school & $\mathrm{X}$ & $\mathrm{X}$ & X/proxy & X/proxy \\
\hline Type of exposure to the disaster & $\mathrm{X}$ & - & $\mathrm{X}$ & - \\
\hline $\begin{array}{l}\text { Emotional reactions during and just after the } \\
\text { disaster (including peri-traumatic dissociation) }\end{array}$ & $x$ & - & $\mathrm{X}$ & - \\
\hline PTSD evaluation (23) & $\mathrm{X}$ & $\mathrm{X}$ & $\mathrm{X}$ & $\mathrm{X}$ \\
\hline Post traumatic growth (24) & - & $\mathrm{X}$ & - & - \\
\hline Description of social consequences & $\mathrm{X}$ & $\mathrm{X}$ & - & - \\
\hline $\begin{array}{l}\text { Description of psychosocial support/interventions by } \\
\text { professionals }\end{array}$ & $x$ & $\mathrm{X}$ & proxy & proxy \\
\hline $\begin{array}{l}\text { Evaluation of contacts with structures of } \\
\text { psychosocial support }\end{array}$ & $\mathrm{X}$ & $\mathrm{X}$ & - & - \\
\hline Evaluation of general health condition* & $\mathrm{X}$ & $\mathrm{X}$ & $\mathrm{X}$ & $\mathrm{X}$ \\
\hline Mental health consequences (SCL90-R)* (25) & $\mathrm{X}$ & $\mathrm{X}$ & - & - \\
\hline Effects on lifestyle (smoking/alcohol use) ${ }^{\star}$ & $\mathrm{X}$ & $\mathrm{X}$ & - & - \\
\hline Effects on drug use* & $\mathrm{X}$ & $\mathrm{X}$ & proxy & proxy \\
\hline Effects on health services utilisation* & $\mathrm{X}$ & $\mathrm{X}$ & proxy & proxy \\
\hline
\end{tabular}

* Questions similar as those used by the Belgian Health Interview Survey (7)

* Proxy: questions filled in by a parent or a close adult 


\section{Health outcomes}

Data on health outcomes were collected through two different auto-questionnaires (Table 2). One questionnaire was addressed to people aged 15 years and older. An adapted questionnaire addressed children aged 8 to 14 years, measuring the same indicators as the adults' questionnaire. Several modules of validated questions were used. As such, the same instruments on physical and mental health as those used in the 2001 Belgian National Health Interview Survey (7) were used, with the aim of comparing the results of the present study to the data of either the total Belgian population or the population of the province of Hainaut.

With regard to mental health, somatisation, anxiety, depression, and sleeping disorders as well as Post-Traumatic Stress Disorder (PTSD) were investigated. With regard to physical health, the study addressed the use of public health services, changes in life style factors, such as smoking and alcohol use, the consumption of psycho-active drugs, and absenteeism at work or school. Some health outcomes were added during the second phase, namely post-traumatic growth which represents the positive changes in the aftermath of a crisis whereby a cognitive process is initiated to cope with the traumatic event (5) and sense of coherence, which is the ability to comprehend, to manage and to give a meaning to the crisis (6).

\section{Exposure classification of the victims}

Disaster victims have often been classified by the extend to which they suffered personal injury and sickness, bereavement or property loss (8). Through the questionnaire, people described their degree of exposure to the disaster. The study population has been classified into 9 categories, based on the individual's proximity to the disaster.

The 9 categories were:

- Persons injured and hospitalised $\geq 72$ hours.

- Persons injured and hospitalised $<72$ hours.

- Persons injured but not hospitalised.

- Persons not injured, but direct witnesses of the explosion as they saw injured or deceased victims. They were present at or nearby the site at the moment of the explosion.

- Local residents living in the surrounding communities. They had heard, seen, smelled, felt, and/or experienced the disaster from a distance.

- Family members or colleagues of deceased or wounded persons.

- Family members or colleagues of persons who could have been deceased or wounded (for example they were coincidentally not present at that moment).

- Other persons who could have been on the industrial site, but were not at that moment. 
Some people were not classified: they were mainly residents exposed to the disaster through the media or they had not been exposed to the disaster in any direct or indirect way (they are not "victims"- they were absent at the moment of the disaster, e.g. on holiday).

For reasons of subsequent analyses, the 9 categories were reduced to 3 major exposure groups, following the criteria of proximity to the disaster:

- Direct witnesses who had seen human damage (SHD). They were direct 'active witnesses' of the explosion, they were present at the epicentre of the disaster.. They are more prone to adverse health consequences due to the witnessing of grotesque scenes at the site and the life treat they have experienced (9). They include the first four categories.

- Direct witnesses who had not seen human damage (NSHD). They were direct 'passive witnesses' of the explosion. They were not closely involved. They include category 5.

- Indirect witnesses have been indirectly exposed to the disaster through an affective proximity with a direct witness (SHD or NSHD). They include categories 6 to 9 .

\section{Results}

\section{Overall response rate}

Five months after the disaster, response rate at household level was 18\% ( $n=607$ families) (Table 1). None of the family members of the 24 deceased persons participated in the study. After three months, trained psychologists contacted 43 (83\%) out of 52 direct victims in order to encourage them to participate. 23 of them agreed to fill in the questionnaire, 9 declined, 11 persons could not be contacted. The response rate at household level was $17 \%$ for the residents living within $5 \mathrm{~km}$ of the epicentre, $23 \%$ for the employees of companies and $25 \%$ for the people who identified themselves to an emergency service or another aid service.

Fourteen months after the disaster, the response rate at household level was $56 \%$ (338 families); this is $9.8 \%$ of the initially study population who received a questionnaire five months after the disaster. We captured 32 adults and 3 children who responded to the $2^{\text {nd }}$ questionnaire only.

\section{Distribution rate by exposure classification}

At 5 and 14 months respectively, the overall distribution by exposure classification was $8.2 \%$ $(n=84)$ and $8.1 \%(n=47)$ for direct witnesses SHD. Among them, 38\% $(n=31)$ were injured and $63 \%$ were not $(n=53)$ at 5 months (Table 3$)$. At 5 and 14 months respectively, the overall distribution by exposure classification was $58.1 \% \quad(n=597)$ and $55.3 \% \quad(n=320)$ for direct witnesses NSHD and $33.7 \% \quad(n=346)$ and $31.1 \% \quad(n=180)$ for indirect witnesses. We investigated whether the response rate at 14 months depended on the exposure classification. The comparison is of interest in drawing inference on further research results 
from the data. The response rate did not differ significantly by exposure classification (Pearson Chi square test: NS at $p=0.47$ ).

Table 3. Distribution of adults (>=15 years old) by exposure classification, exposed to the disaster by geographical (resident) or professional (working in company) proximity 5 months and 14 months after the disaster

\begin{tabular}{|c|c|c|c|c|c|c|}
\hline & \multicolumn{2}{|l|}{ Resident } & \multicolumn{2}{|c|}{ Working in company } & \multicolumn{2}{|l|}{ Total } \\
\hline & 5 months & 14 months & 5 months & 14 months & 5 months & 14 months \\
\hline & $N(\%)$ & $N(\%)$ & $N(\%)$ & $N(\%)$ & $N(\%)$ & $N(\%)$ \\
\hline 1) Direct witness, SHD* & $52(5.8 \%)$ & $27(5.6 \%)$ & $32(21.8 \%)$ & $20(21.1 \%)$ & $84(8.2 \%)$ & $47(8.1 \%)$ \\
\hline Injured \& hospitalised $>72 \mathrm{~h}$ & 3 & 2 & 18 & 11 & 21 & 13 \\
\hline Injured \& hospitalised $<72 \mathrm{~h}$ & 1 & 1 & 6 & 4 & 7 & 5 \\
\hline Injured, not hospitalized & 1 & 0 & 2 & 2 & 3 & 2 \\
\hline $\begin{array}{l}\text { Direct witness of human } \\
\text { damage }\end{array}$ & 47 & 24 & 6 & 3 & 53 & 27 \\
\hline 2) Direct witness, NSHD* & $579(65.8 \%)$ & $307(63.4 \%)$ & $18(12.2 \%)$ & $13(13.7 \%)$ & $597(58.1 \%)$ & $320(55.3 \%)$ \\
\hline 3) Indirect witness & $249(28.4 \%)$ & $124(25.6 \%)$ & $97(66.0 \%)$ & $56(58.9 \%)$ & $346(33.7 \%)$ & $180(31.1 \%)$ \\
\hline $\begin{array}{l}\text { Close person or colleague } \\
\text { dead or injured }\end{array}$ & 44 & 22 & 64 & 34 & 108 & 56 \\
\hline $\begin{array}{l}\text { Close person/colleague could } \\
\text { have been hurt, but was not }\end{array}$ & 33 & 15 & 2 & 2 & 35 & 17 \\
\hline $\begin{array}{l}\text { Others, could have been on the } \\
\text { site but were not }\end{array}$ & 158 & 81 & 30 & 20 & 188 & 101 \\
\hline No classification & 14 & 6 & 1 & 0 & 15 & 6 \\
\hline Others (Quest. 2) & & $26(5.4 \%)$ & & $6(6.3 \%)$ & & $32(5.5 \%)$ \\
\hline Total & $880(100 \%)$ & $484(100 \%)$ & 147 (100\%) & $95(100 \%)$ & $1027(100 \%)$ & $579(100 \%)$ \\
\hline
\end{tabular}

* SHD =Seen human damage, NSHD =Not seen human damage

\section{Discussion}

The study population included all people who could possibly have been touched by the disaster. No exclusion criteria were established. The overall response rate at household level at 5 months was $18 \%$. In order to increase the response rate among the direct victims, they were contacted by psychologists who tried to motivate them to participate in the study. But 
the majority of the people who declined to participate did not want to be confronted with the disaster again. Finally, our study population represents only $8 \%$ direct witnesses, SHD $(n=84)$. Among them, only one third was injured $(38 \%)$ and $63 \%$ were not. Generally, about 132 people were known to be injured during the disaster; however the database could only capture 31 of them. The bureaucratic and political problems that led to the delay in the onset of the investigation could account for this low number of direct witnesses SHD in the database. This pitfall raises question on the study representativeness. The possible selection bias could result in an under representation of severely affected victims. If we would have been able to capture most of the injured victims, knowing that they are more likely to participate in a study on disasters (4), the investigators probably would have increased the response rate for this subpopulation significantly.

Fourteen months after the disaster, the response rate at household level was $56 \%$. A comparable response rate from all different sub-groups within a sample is desirable. The response rate in this study did not differ significantly by exposure classification. This contrasts the expectation of a differential response rate among the 3 exposure groups as each of them may be using different coping mechanisms to the disaster effect and may feel differently affected by the consequences of the disaster.

The low response rate for the first questionnaire necessitates careful interpretation of subsequent results. Differences in respondent characteristics may lead to bias in prevalence estimates and bias in associations. Studies of representative samples of the population are theoretically the best approach to examine the prevalence of health effects (10). A high response rate is essential to ensure the representativeness and generalisability of the results of the study. The methods used to contact the population need to be considered. A crosssectional study, conducted 18 months after the AZF factory explosion in Toulouse (France) among adults over 18 , reached a participation rate of $60 \%$. They used questionnaires that had to be completed during a face-to-face interview (10). Face-to-face interviews or telephone surveys have been reported to have higher response rates than mailed questionnaires (10). However, a response rate of $20 \%$ is considered normal for a postal questionnaire (11). On the other hand, it has been found that when survey methods such as questionnaires are used, then the return rates are much lower than in non-disaster settings (12). Similar research on disasters in the Netherlands has reported higher response rates. Survey participation rate 3 weeks after a major firework disaster in Enschede was 26\% (adults residents $\geq 18$ years old) (4). The higher response rate could be a result of the shorter time interval between the disaster and the first measurement ( 3 weeks instead of 5 months in the present research). Response rate at 18 months was $54 \%$ among immigrants and $81 \%$ among native Dutch persons (13) with an overall response rate of $72 \%$ (14). They concluded that health problems were associated with higher response among non-Western immigrants and with lower response among the native Dutch.

Not responding to the present study could have 3 different causes. First, people might not have been able to answer the questionnaire due to hospitalization or recovery, be it physical 
or emotional. A lot of them may not have wanted to be confronted once again with the disaster. This hypothesis is more likely among direct witnesses SHD. This would lead to an underestimation of the health outcomes. Secondly, it is possible that those living further away from the epicentre of the disaster have not filled in the questionnaires because they did not feel involved or concerned with the disaster. This could apply to direct witnesses NSHD as they "could" have experienced the disaster from a distance. This applies also for indirect witnesses. It could lead to a non-response bias related to the exposure. Those who participated could be different from those who did not. If so, it could have a negative influence on the generalisability of the study results for that study group. Next, the study was not integrated in the global management of the disaster. Several institutions approached the affected people and asked for information about the disaster requiring a lot of paperwork to be filled in. People might have felt disappointed about the management of the disaster by the government. Some of the victims have been discouraged by caregivers of psychosocial support structures to fill in yet another questionnaire. At the same time, there were parallel studies, not financed by the government, which gave an uncoordinated impression to the population and might have lead to confusion. All of this might have had a negative influence on the response rate.

Researchers encountered other difficulties which could have influenced the response rate. Firstly, it took about 4 months of negotiations with the authorities before the study was approved. The time interval between the gas explosion and the first point of measurement was 5 months. Secondly, the researchers dealt with difficulties in the collection of the necessary addresses of the affected people. There was a lack of co-ordination between the different governmental departments (both local and federal), or organizations involved. Each of them claimed the exclusive right to manage the confidential data on the disaster victims. Several address lists of victims were generated in parallel, and they were never really compared by one governing body. As a consequence, the list of direct victims who were present at the site during the explosion was not made available in time; moreover, not all direct victims could be contacted. Finally, the household composition at 5 months was not known for 158 families. A set of 6 questionnaires had been sent to those households. A standard household composition counts on average 4 family members. This fact could have led to an underestimation of the true response rate due to those missing denominator data.

Several studies describing the impact of disasters on (mental) health deal with methodological problems which could be related to the use of different definitions concerning the classification of the different exposure groups $(16,17)$. The exposure classification of the Ghislenghien disaster victims is related to the individual's proximity to the disaster. The hypothesis was made that health problems of the defined groups would initially depend on the extent to which they witnessed or suffered personal injury, secondly on the degree of geographical distance to the explosion, and thirdly on the type of involvement through family or close connections. Disaster victims often have been classified by the extent to which they suffered personal injury, bereavement or property loss (18). Others differentiated groups according to the type of involvement, their function, their capability, their self-control and 
certain extraneous factors (19). The classification made in our study lies closely to the classification used in the Volendam fire disaster, in the Netherlands, where the different groups depended on the degree and type of losses experienced (8).

Limitations of the study in summary

The sudden aspect of this technological disaster has put time pressure on the development of the study protocol as we dealt with complicated socio-political and legal issues. Next, we faced a number of methodological problems, this include the definition of the entire potentially 'affected' population. In addition to the direct victims being on the site of the disaster, a rather large group of residents were included into the study population in order not to miss any potentially affected victim. It was further difficult to contact and motivate the most affected victims (wounded and hospitalized participants, family members of deceased persons). None of the family members of deceased persons answered the questionnaire.

Strengths of the study

The first strength of the study is that we have included several sets of validated and widely used questions on mental, physical and social health which also have been used by the Belgian health interview survey (7) as a reference population. Secondly, our target group composed of all potential victims including family and children. This added value, given that traumatic experiences and stressful life events frequently involve the entire support system of the victim (8). Finally, people may answer in a different way in the aftermath of a disaster due to the social impact on the public as a whole inducing observation bias (attention given to the affected population, media). But, in order to avoid observation bias during the second phase, the $2^{\text {nd }}$ questionnaire was sent 14 months instead of 12 months after the disaster when a lot of attention was given in the media due to the one-year memorial of the disaster.

The significance of the study for the management of large scale emergencies in Belgium

This research provides knowledge about the long-term health consequences of technological disasters. Recommendations presented to the authorities stress the need to take care of and to follow up the victims. Local general health practitioners, psychosocial actors, other professionals and the authorities should be more involved and their involvement should be structured into future disasters. This requires a multidisciplinary and proactive approach (20).

As in other countries, the concept of emergency planning in Belgium is regularly evaluated. Since 1997, the Federal Public Service for Health has developed a Psycho Social Intervention Plan (PSIP) within the framework of a medical-sanitary aid service during collective emergencies. The disaster of Ghislenghien forced the Belgian authorities to reevaluate their approach towards the management of disasters. It was recommended that a federal structure should be set up to deal with the coordination and gathering of information related to the victims of a disaster whereby the physical, mental and social health of the potentially affected population is "systematically" assessed and monitored. Our study took so long to be set up because no such structure existed. An independent structure, such as the 
National Institute of Public Health could be charged with the evaluation of its intervention; this institute has the experience in handling sanitary crisis situations in Belgium. A systematic evaluation strategy should exist, as in other Western countries such as the Netherlands and the United States. Their role should be to evaluate the health consequences in the aftermath of a disaster in order to evaluate the efficacy of the medico-psycho-social interventions that have taken place.

Nowadays, psychosocial aid is a formal part of the second discipline of the emergency and intervention plan as outlined in the PSIP scenario (Royal decree concerning the emergency and intervention planning, February 16 2006) (21). As such, the PSIP aims to provide quality of care provided to affected people through the use of a standard reference frame at the federal level. Furthermore, it also had an effect on the tasking priorities of the existing Psycho Social Managers (PSMs). The collaboration of PSMs, whose function it is to coordinate the psychosocial assistance for disaster survivors would of course be most appreciated if such a systematic evaluation was (ideologically and financially) supported. Indeed, their task is on the one hand preventive, whereby the PSMs are constructing a psycho-social network on the basis of the existing psycho-social services. On the other hand, their role is operational, whereby the PSMs are coordinating the psycho-social care of disaster victims on the basis of the PSIP. In this way, the local services can be more efficiently organized, as they can use a specific coordination structure that always assesses the needs of victims, the available resources and the actions taken toward the benefit of victims (22). Thus, PSMs could help in dealing with the collection of important information on the victims that would be used in the identification of potentially affected victims and their inclusion in a study on their health.

\section{Acknowledgments}

The study was funded by the Federal Public Service Health, Food Safety and Environment. We also thank Prof. Dr Rolf Kleber (Utrecht University) and Prof. Dr Onno van der Hart (Utrecht University) who provided advice with respect to our conceptualisation of psychological trauma and the importance of peritraumatic dissociation for inclusion in the questionnaire.

\section{References}

1. De Soir E, Zech E, Versporten A, Van Oyen H, Kleber R, Van Der Hart O et al. Prédiction de I'ESPT lors d'une catastrophe technologique. Revue Francophone du Stress et du Trauma 2008 ; 8: 211-24

2. Binder S, Sanderson LM. The role of the epidemiologist in natural disasters. Ann Emerg Med 1987; 16(9):1081-4

3. Noji EK. Disaster epidemiology and disease monitoring. J Med Syst 1995; 19(2):171-4

4. Grievink L, van der Velden PG, Yzermans CJ, Roorda J, Stellato RK. The importance of estimating selection bias on prevalence estimates shortly after a disaster. Ann Epidemiol 2006; 16(10):782-8

5. Hoyle Leigh. Stress: Positive and Negative Effects. Posttraumatic Growth: Positive Changes in the Aftermath of Crisis. Am J Psychiatry 2000; 157(10):1712 [Book review] 
6. Antonovsky A. The structure and properties of the sense of coherence scale. Soc Sci Med 1993; 36(6):725-33

7. Demarest S, Van der Heyden J, Gisle L, Buziarsist J, Miermans PJ, Sartor F et al. Belgian Health Interview Survey - Results. IPH/EPI REPORTS N²002 - 25. 2002. Brussels, Scientific Institute Public Health

8. Dorn T. Health impact of the Volendam disaster. Utrecht: NIVEL, 2007

9. Norris FH, Friedman MJ, Watson PJ. 60,000 disaster victims speak: Part II. Summary and implications of the disaster mental health research. Psychiatry 2002; 65(3):240-60

10. Lang T, Schwoebel V, Diene E, Bauvin E, Garrigue E, Lapierre-Duval K et al. Assessing post-disaster consequences for health at the population level: experience from the AZF factory explosion in Toulouse. J Epidemiol Community Health 2007; 61(2):103-7

11. Health Interview Surveys. 1996. Copenhagen, World Health Organisation

12. Logue JN, Melick ME, Hansen H. Research issues and directions in the epidemiology of health effects of disasters. Epidemiol Rev 1981; 3:140-62

13. Dijkema MB, Grievink L, Stellato RK, Roorda J, van der Velden PG. Determinants of response in a longitudinal health study following the firework-disaster in Enschede, The Netherlands. Eur J Epidemiol 2005; 20(10):839-47

14. Van Den Berg B., van der Velden PG, Joris YC, Stellato RK, Grievink L. Health-related quality of life and mental health problems after a disaster: are chronically ill survivors more vulnerable to health problems? Qual Life Res 2006; 15(10):1571-6

15. Ursano RJ, Fullerton CS. Trauma, time and recovery. Posttraumatic stress disorder. Acute and Long-term responses to trauma and disaster. Washington DC: American Psychiatric Press, 1997: 269-75

16. Brewin CR, Andrews B, Valentine JD. Meta-analysis of risk factors for posttraumatic stress disorder in trauma-exposed adults. J Consult Clin Psychol 2000; 68(5):748-66

17. Raphael B, Wilson J. Theoretical and intervention considerations in working with victims of disaster. International handbook of traumatic stress syndromes. 1993: pp. 105-17

18. Dohrenwend BP, Dohrenwend BS, Warheit GJ, Bartlett GS, Goldsteen RL, Goldsteen K et al. Stress in the community: a report to the President's Commission on the Accident at Three Mile Island. Ann N Y Acad Sci 1981; 365:159-74

19. Taylor AJ. A taxonomy of disasters and their victims. J Psychosom Res 1987; 31(5):535-44

20. Versporten A, Zech E, De Soir E, Van Oyen H. Etude de l'impact de la catastrophe de Ghislenghien sur l'état de Stress Post-Traumatique et sur la santé de la population. IPH/EPI REPORTS Nr. 2006-025. 2006. Brussels, Belgium, Scientific Institute of Public Health

21. Allaert E. Psychosociaal management binnen de discipline "medische, sanitaire en psychosociale hulpverlening" in de noodplanning. Eindverhandeling stage niveau A. 2008. FOD Volksgezondheid, Veiligheid van de Voedselketen en Leefmilieu., Directoraat-generaal Basisgezondheidszorg en Crisisbeheer

22. https://portal.health.fgov.be/portal/page?_pageid=56,841655\&_dad=portal\&_schema=PORTAL 2008

23. APA, American Psychiatric Association. Diagnostic and Statistical Manual for Mental Disorders. 4th Edition ed. Washington D.C.: 1994

24. Tedeschi RG, Calhoun LG. The Posttraumatic Growth Inventory: measuring the positive legacy of trauma. J Trauma Stress 1996; 9(3):455-71

25. Derogatis LR. SCL-90_R (revised) version Manual I. 1977 